Dr. S. G. Ankaliki, Dr. A. D. Kulkarni, Prof. Sujata I. Katti / IOSR Journal of Engineering

(IOSRJEN)

Www.iosrjen.org

ISSN : 2250-3021

Vol. 2 Issue 2, Feb.2012, pp.356-362

\title{
Hierarchical Compensation Technique for Loss Minimization in Distribution System
}

\author{
${ }^{1}$ Dr. S. G. Ankaliki, ${ }^{2}$ Dr. A. D. Kulkarni, ${ }^{3}$ Prof. Sujata I. Katti \\ ${ }^{l}$ Professor E \& E Engineering, SDM College of Engineering and Technology (SDMCET), Karnataka, India \\ ${ }^{2}$ Professor E \& E Engineering, National Institute of Engineering, Mysore, , Karnataka, India \\ ${ }^{3}$ Assistant Professor, E \& E Engineering, Hirasugar Institute of Technology, Nidasoshi-591 236
}

\begin{abstract}
This paper presents hierarchical compensation technique for loss minimization in distribution system by optimum location of capacitor. The electric distribution system serves an important role in achieving satisfactory power supply. The power quality is measured by good voltage profile and voltage stability. In addition the distribution system should be operated under optimum loss condition. In view of recent power sector reforms lot of emphasis has been given to these aspects. In order to get optimized operating condition the reactive compensation methodology is adapted. The proposed approach identifies the proper location $\&$ size of compensation depending on the main feeder, laterals, and sub laterals owing to their hierarchy. The cost analysis gives the amount of saving achieved per annum. The approach is tested on 15 bus test distribution system. The technique serves as a useful tool for optimized distribution system operation.
\end{abstract}

Key words: Distribution System, Loss Reduction, Load Flow.

\section{INTRODUCTION}

Energy is the most vital tool for an economical development and social transformation for all the developed and developing countries of the world. Unless there is adequate supply of energy the development targets and economical growth cannot be achieved. Per capita consumption of electricity is the index of national economic development. A properly designed and operated power system should meet the following fundamental requirements [1];

i) The system must be able to meet the continually changing load demand for active and reactive power. Since electricity cannot be conveniently

ii)stored in sufficient quantities, adequate spinning reserve should be maintained.

iii) The system should supply energy at minimum cost and with minimum ecological impact. iv) The quality of power supply must meet certain minimum standards with regard to the following factors;

- constancy of frequency

- constancy of voltage

- level of reliability

\section{LITERATURE REVIEW}

Several methods of loss reductions in distribution system through allocations of shunt capacitor have developed over the years. The calculation of voltages for radial distribution system by backward sweep method [2] is presented. Shunt capacitors are installed to appropriate locations in large distributions systems to reduce power and energy losses and to improve voltage profile along the feeder. The procedure to calculate loss minimization by placing capacitor at the nodes where the cost saving is maximum. This is carried for both single capacitor and also multiple capacitors [3]. A generalized procedure is developed for optimizing the net momentary savings associated with the reduction of power and energy losses, through placements of fixed and switched shunt capacitors on primary distributions feeders [4]. The complexity of this problem differs significantly from placing only fixed banks because of the switching time of switched banks represents another variable to be determined. A solution to the volt/var problem in distribution system by decoupling the capacitor and regulator problems and combining them into a global solution determined analytically [5]. The real size of the feeder was considered by introducing the concept of 'normalized equivalent feeder'. The method [6] is developed for control of reactive power in the distribution systems with an end load for fixed load and varying load conditions, give generalized equations for calculating the peak power and energy losses reduction and the optimum location and rating of capacitor. In contrast of these analytical optimization techniques heuristic search strategies have been recently developed. The purpose of developing such heuristic techniques is to decrease the exhaustive search space, while keeping the end 
Dr. S. G. Ankaliki, Dr. A. D. Kulkarni, Prof. Sujata I. Katti / IOSR Journal of Engineering

(IOSRJEN) www.iosrjen.org

ISSN : 2250-3021

Vol. 2 Issue 2, Feb.2012, pp.356-362

result at optimal or near optimal value. The advantages of the heuristic techniques are very well appreciated for large distribution systems, by providing realistic sizes and locations for shunt capacitors on primary feeder at a relatively low computation burden. A formula to estimate the loss change resulting from the transfer of a group of loads from one feeder to another feeder by the closing of single tie switching and the opening of a single sectionalizing switch [7]. A method is described for reconfiguration with the potentials for handling realistic operating constraints [8]. The approach taken is to set up a decision tree to represent the various switching operations available. This method has been implemented in knowledge base environment. The difficulty in network reconfiguration problem is that the number of connections becomes formidable and it is impossible to analyze every combination for the reduction in the network loss in each tree formed out of that combination. Although the papers mentioned above are in the area of feeders' configuration of loss reduction, they present some valuable ideas that can be employed in capacitor placement optimization. Adapted a kind of heuristic search to the problem of capacitor placement according to this method the largest loss section of primary feeder is determined and then the node with the highest impact on the losses in that section is detected and compensated [9]. The heuristic approach is proposed where a small number of critical nodes, named sensitive nodes are selected for installing capacitors that optimize the net savings while achieving a large overall loss reduction [10]. Recently artificial neural network based distribution system line loss estimation is presented in [13]

\section{IMPORTANCE OF DISTRIBUTION SYSTEM}

The greatest challenge that the power engineers face today is to evolve a cheap reliable primary and secondary power distribution system. Technology offers solution for many problems related to power system such as to reduce the losses and to ensure the reliable operation and distribution of the power. Electric power distribution is a vital link between utility and the consumer, thus playing a very important role in the entire power system network. The investment in the distribution system is around 30 to $40 \%$ of the total investment of the entire power system. Per unit cost of energy of distribution system is highest as the cost of this system is cumulative of the preceding systems. Hence it is imperative to exercise utmost caution in planning the system with losses as low as possible and a better quality of supply to the consumers. In the context of chronic power supply and the ever increasing prices of fuel, it assumes greater importance. But unfortunately, this distribution system is not receiving as much attention as it ought to have. The major amount of transmission and distribution losses occurs in the distribution system. This is obviously due to less attention being given to distribution system network. Improper planning not only reflects in the form of increased investments and less revenue utility, but also, in the form of decreased systems capacity which would otherwise have been usefully utilized with effective increase in the system capacity. This also causes consumers dissatisfaction, as the voltage at the consumer terminals is normally poor.

\section{POWER SYSTEM LOSSES}

Significant portion of power in power system is lost in transmission and distribution network due to system losses [11]. It has estimated that each $\mathrm{kW}$ of energy saved from these transmission and distribution losses would result as much as $3 \mathrm{~kW}$ or more of the fuel energy. As a result of increased energy cost and the demand outstripping the availability, the improvement of system performance by reduction of energy losses has assumed importance. The present level of transmission and distribution losses in Indian utilities is estimated to be around 26 to $27 \%$. The losses are high compared to accepted international norms.

\section{Analysis of Losses}

A critical analysis of losses in the power system and the way to quantify the losses occurring in various elements of power system is necessary before understanding a detailed review of measures for reduction of losses.

\section{Classification of Losses}

The transmission and distribution losses comprise technical losses and commercial/unaccounted losses. The technical losses occur due to energy dissipation in the conductor and equipment used for transmission and distribution of power due to there inherent characteristics. These losses can be reduced substantially from the existing level but could not be eliminated completely. The commercial/unaccounted losses are attributable to intentional act of unscrupulous person resorting to pilferage of energy and energy meters becoming defective due to poor quality and un-metered supply.

\section{Factors Influencing Losses}

- Primary and secondary feeders that extend over a long distance to feed loads which cover large areas. These feeders are extended indiscriminately over very long distances resulting in increase line losses and poor voltage regulation. 
Dr. S. G. Ankaliki, Dr. A. D. Kulkarni, Prof. Sujata I. Katti / IOSR Journal of Engineering (IOSRJEN) www.iosrjen.org

ISSN : 2250-3021

\section{Vol. 2 Issue 2, Feb.2012, pp.356-362}

- Improper selection of conductor size to feed this leads also contributes to a very significant extent to the line losses and very poor voltage regulation.

- The distribution transformers are not placed at the center of gravity of loads which results in extremely low voltage at the farthest consumer points even through a reasonable voltage level is maintained near the transformers. This also leads to higher losses due to increased current in the feeder.

- Pattern of energy consumption, viz, percentage agriculture consumption, percentage energy consumed by bulk industries ratio of HT to LT line consumption.

- Power factor and load factor of load

- Configuration of system, namely, length of the line, ratio of HT to LT line length, length of HT lines per transformer, and number of transformers.

- Poor workmanship like loose connections, improper connections to the transformer bushing system, drop out fuse, isolator, LT switch etc., also contributes to existence of higher losses and poor voltage regulation.

\section{MEASURES FOR LOSS REDUCTION}

The following are the various measures for loss reduction;

\section{Improvements in System Configuration}

In this method, the system configuration is improved so as to bring it closer to an optimally designed network. This requires a study of load flow and loss calculations as well as the topology of the network. Based on a rigorous study, it is possible to decide on rerouting distribution lines over certain sections, minimizing the length of feeders and also the location of new substations. By this means effective line lengths are reduced and considerable loss reduction is possible. At the same time overall distribution system performance and voltage profile can be improved. This method basically involves reducing the line lengths by either rerouting or by adding new feed points [10]. However this method requires a detailed study for each distribution system and the required data are not easily available. Data collection and its further analysis using sophisticated computer techniques require substantial time and effort. Because of this, this type of improvements in distribution system has not been as extensively used as they deserve to be.

\section{Improvements to the Existing Systems}

In this type of improvements, without change of system configuration, the distribution losses can be reduced by replacing heavily loaded sections of the line by larger suitable conductor sizes and by the applications of static capacitors. The method of replacing with larger sizes requires maximum line work and considerable labour force. However, this is one of the best methods for loss reduction as this method of improvement does not add any special maintenance or any other problems. Further the field labour force is already available with fully equipped to carryout line stringing and dismantling operations. While it is recognized that a proper cost-benefit check must be made based on conductor and restringing cost versus cost of losses, 'rule of thumb' can be generally be applied. It should be general directive to all maintenance crews in carryout replacing work whenever possible.

\section{Use of Static Capacitors}

Another method, which can be used without changing the system configuration, is the use of static capacitors. The use of static capacitors for loss reduction has been intensively studied and very sophisticated computer methods are available to decide on the optimum location of capacitors. Here also the cost benefit ratio to be computed to compare the saving in cost due to reduction in energy losses.

\section{Optimizing Line Capacity}

Selecting appropriate KVA-KM capacity based on the required voltage regulation and normal power factor for the conductor used in LT distribution circuits. Select appropriate MW-KM capacity for the standard conductors used in the primary distribution, thereby limiting lengths of primary feeders.

\section{Optimizing Transformer Capacity, Location and Use}

Selecting appropriate capacity and location of distribution transformers in relation to the consumers fed by it to keep voltage drops to a minimum. Optimize the use of distribution transformers based on load factor occurring on them.

\section{PROBLEM FORMULATION}

A typical radial distribution network will have only one controlled node and it will have lateral taps on primary main feeder and the lateral taps themselves will also be tapped. A typical section is shown in the Fig. 1. The requirement of the load flow program is to compute the voltage at every node and losses in the all the sections as fast and accurately as possible. 
Dr. S. G. Ankaliki, Dr. A. D. Kulkarni, Prof. Sujata I. Katti / IOSR Journal of Engineering (IOSRJEN) www.iosrjen.org

ISSN : 2250-3021

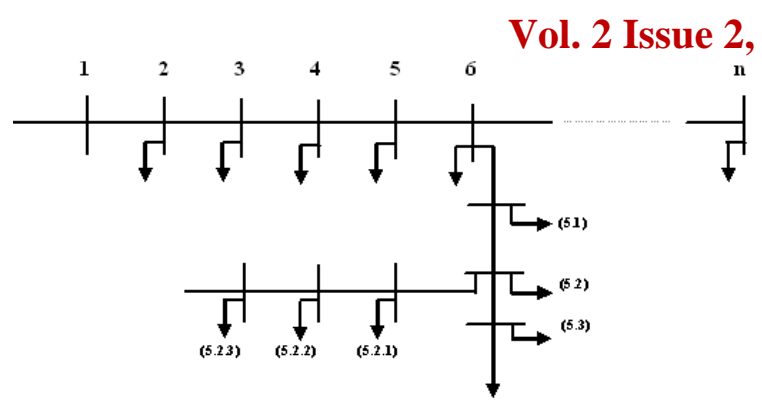

Fig.1. Schematic of Distribution System Section

\begin{abstract}
Hierarchical Compensation Techniques for Loss Minimization

In general, a distribution system is fed at only one point and the structure of the network is mainly radial. For such a system all the active power demands and losses must be supplied by source at the root bus, However addition of shunt capacitors can generate reactive power demand and losses from the source. Thus, there is a provision to minimize the loss associated with reactive power flow through the branches.
\end{abstract}

\section{PROPOSED METHOD}

The proposed method first identifies a sequence of nodes to be compensated. The sequence is determined by repetitive changing of capacitors drastically at each node and the node, which has the highest cost of loss, saving is identified and is compensated. The required voltages at each node and branch currents of the radial network are calculated from the load flow technique. The total loss of the radial system is given by

$$
\mathrm{TPL}=\sum_{\mathrm{j} \mathrm{j}=1}^{\mathrm{LN} 1} \mathrm{I}^{2}(\mathrm{jj}) \mathrm{R}_{(\mathrm{jj})}
$$

\section{First level of compensation}

The capacitor size of each node on the main feeder is changed drastically and voltages at each and branch currents are calculated. Then the new total loss of the radial system is given by

$$
\mathrm{TPL}^{\mathrm{com}}=\sum_{\mathrm{jj}=1}^{\mathrm{LN} 1} \mathrm{I}^{2}{ }_{(\mathrm{jj})}{ }^{\text {new }} \mathrm{R}_{(\mathrm{jj})}
$$

The loss saving $\mathrm{S}$ is the difference between equation (1) \& (2)

$\mathrm{S}=\mathrm{TPL}-\mathrm{TPL}^{\mathrm{com}}$

Maximize net cost of loss saving (Rs)

$=\mathrm{S}^{*}$ cost of power loss $-\mathrm{Qc} *$ cost of capacitor (4)

The highest possible saving of cost of loss for a capacitor at a particular bus is identified and that particular capacitor size is taken as optimum size and that particular bus is compensated.

\section{Second level compensation}

After finding the optimal size of capacitor on the main feeder and placing the capacitor at that particular node, the same procedure is carried out for the lateral feeder and the node that is to be compensated is identified. This can be carried out to sub-laterals of the system until the hierarchy is achieved.

\section{ALGORITHM}

The computational steps involved in finding the optimal capacitor size and location to minimize the loss in a radial distribution system are summarized as

Step 1: Run the load flow program and obtain the branch currents and total loss of the system.

Step 2: Vary the capacitor size at node, except the first node and run the load flow and calculate the new branch current and loss of the system. Repeat this step for all the buses in the system and identify the bus that provides the highest cost of loss saving.

Step 3: The identified bus is compensated and step (2) is repeated for the lateral buses in the system and the bus that provides the highest cost of loss saving is compensated.

Step 4: Next, the same procedure is carried out to the sub-lateral until the hierarchy is achieved.

\section{CASE STUDY:}

\section{$11 \mathrm{kV}$ 15-BUS DISTRIBUTION SYSTEM}

In this paper radial distribution system is considered for the loss minimization. Power flow analysis is used to find the voltage profile along the feeders. Improvements in the voltage profile and loss reduction by the application of capacitors is obtained. Loss charges per $\mathrm{kW}=$ Rs. 3. Operating cost of capacitors $=10 \%$ of capital cost. Capital cost $=$ Rs. $1200 / \mathrm{kVAr}$ and hence operating cost of capacitor = $120 / \mathrm{kVAr}$. The single line diagram of the $11 \mathrm{kV} 15-$ bus system is shown in Fig. 2 and system data in Table-1

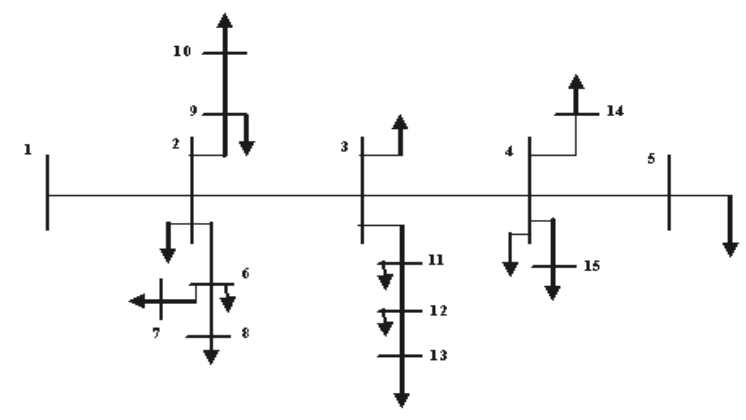

Fig.2. 11kV 15-Bus Distribution System

Table-1: Line Data for 15-Bus System 
Dr. S. G. Ankaliki, Dr. A. D. Kulkarni, Prof. Sujata I. Katti / IOSR Journal of Engineering (IOSRJEN) www.iosrjen.org

ISSN : 2250-3021

Vol. 2 Issue 2, Feb.2012, pp.356-362

\begin{tabular}{|c|c|c|c|c|c|c|}
\hline & Node & Node & & & & \\
\hline 1 & 1 & 2 & 44.1 & 44.99 & 1.35309 & 1.32349 \\
\hline 2 & 2 & 3 & 70.0 & 71.414 & 1.17024 & 1.14464 \\
\hline 3 & 3 & 4 & 140 & 142.82 & 0.84111 & 0.82271 \\
\hline 4 & 4 & 5 & 44.1 & 44.99 & 1.52348 & 1.02760 \\
\hline 5 & 2 & 9 & 70.0 & 71.414 & 2.01317 & 1.35790 \\
\hline 6 & 9 & 10 & 44.1 & 44.99 & 1.68671 & 1.13770 \\
\hline 7 & 2 & 6 & 140 & 142.82 & 2.55727 & 1.72400 \\
\hline 8 & 6 & 7 & 140 & 142.82 & 1.08820 & 0.73400 \\
\hline 9 & 6 & 8 & 70.0 & 71.414 & 1.25143 & 0.84410 \\
\hline 10 & 3 & 11 & 140 & 142.82 & 1.79553 & 1.21110 \\
\hline 11 & 11 & 12 & 70.0 & 71.414 & 2.44845 & 1.65150 \\
\hline 12 & 12 & 13 & 44.1 & 44.99 & 2.01317 & 1.35790 \\
\hline 13 & 4 & 14 & 70.0 & 71.414 & 2.23081 & 1.50470 \\
\hline 14 & 4 & 15 & 140 & 142.82 & 1.19702 & 0.80740 \\
\hline
\end{tabular}

\begin{tabular}{|l|l|l|l|l|}
\hline 11 & 700 & 72.69 & 26.96 & 624000 \\
\hline 12 & 500 & 110.00 & 21.51 & 505400 \\
\hline 13 & 400 & 150.00 & 18.08 & 427300 \\
\hline 14 & 500 & 89.00 & 25.35 & 594000 \\
\hline 15 & 500 & 110.00 & 23.00 & 540000 \\
\hline
\end{tabular}

Table-3: Comparison of Voltage Profile without and with First Level Compensation

\begin{tabular}{|c|c|c|}
\hline \multirow{2}{*}{$\begin{array}{c}\text { Bus } \\
\text { No. }\end{array}$} & $\begin{array}{c}\text { Without } \\
\text { Compensation }\end{array}$ & $\begin{array}{c}\text { With First Level } \\
\text { Compensation }\end{array}$ \\
\cline { 2 - 3 } & Bus Voltage in pu & Bus Voltage in pu \\
\hline 1 & 1.0000 & 1.0000 \\
\hline 2 & 0.9713 & 0.9830 \\
\hline 3 & 0.9566 & 0.9784 \\
\hline 4 & 0.9509 & 0.9727 \\
\hline 5 & 0.9499 & 0.9718 \\
\hline 6 & 0.9619 & 0.9736 \\
\hline 7 & 0.9612 & 0.9729 \\
\hline 8 & 0.9593 & 0.9711 \\
\hline 9 & 0.9652 & 0.9769 \\
\hline 10 & 0.9635 & 0.9752 \\
\hline 11 & 0.9499 & 0.9715 \\
\hline 12 & 0.9458 & 0.9670 \\
\hline 13 & 0.9445 & 0.9654 \\
\hline 14 & 0.9439 & 0.9659 \\
\hline 15 & 0.9415 & 0.9635 \\
\hline
\end{tabular}

As a first step, the load flow study is conducted. Table-2 gives the optimal capacitor rating, location and net saving of the system. The total loss of the system before compensation is $\mathbf{7 7 . 1 7}$ $\mathbf{k W}$ and the loss charge per annum is Rs. 20, 28,000. If an optimal capacitor size of 1000 $\mathrm{kVAr}$ is placed at Bus-3 a maximum net saving of Rs 7, 19, 420 is obtained. Table-3 gives the comparison of voltage profile without and with First level compensation and Fig.3 gives the graphical representation of comparison of voltage profile without and with First level compensation for 15-Bus distribution system.

Table-2: Economical Comparison of Compensation

\begin{tabular}{|c|c|c|c|c|}
\hline $\begin{array}{c}\text { Bus } \\
\text { No. }\end{array}$ & $\begin{array}{c}\text { Optimum } \\
\mathbf{k V A r}\end{array}$ & $\begin{array}{c}\text { Total loss with } \\
\text { compensation } \\
\mathbf{k W}\end{array}$ & $\begin{array}{c}\text { Saving } \\
\text { in } \mathbf{k W}\end{array}$ & $\begin{array}{c}\text { Net saving of } \\
\text { Cost in } \\
\text { Rs per annum }\end{array}$ \\
\hline 2 & 1200 & 51.40 & 25.76 & 533180 \\
\hline $\mathbf{3}$ & $\mathbf{1 0 0 0}$ & $\mathbf{4 9 . 4 0}$ & $\mathbf{3 1 . 9 0}$ & $\mathbf{7 1 9 4 2 0}$ \\
\hline 4 & 900 & 57.30 & 30.90 & 705210 \\
\hline 5 & 600 & 86.78 & 22.61 & 522000 \\
\hline 6 & 500 & 100.00 & 15.20 & 339000 \\
\hline 7 & 500 & 82.41 & 16.28 & 355000 \\
\hline 8 & 400 & 110.00 & 11.99 & 267200 \\
\hline 9 & 600 & 87.10 & 17.28 & 382000 \\
\hline 10 & 500 & 110.00 & 14.25 & 314000 \\
\hline
\end{tabular}

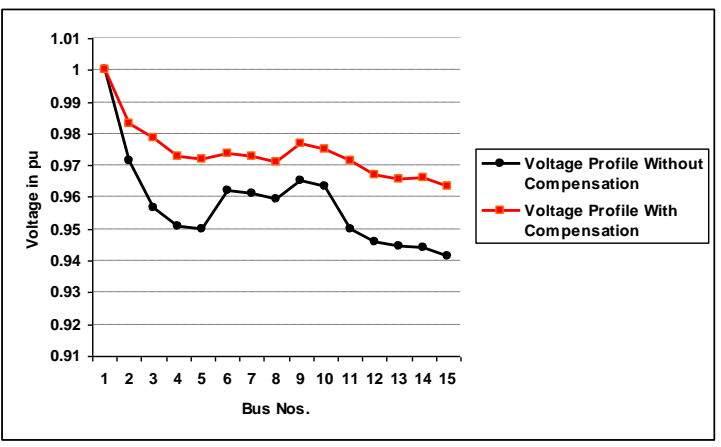

Fig. 3 Voltage Profile without and with Compensation

\section{Second Level Compensation}

Table-4 gives the optimal capacitor rating and net saving of the system in the lateral feeder. If an optimum capacitor size of $200 \mathrm{kVAr}$ is 
Dr. S. G. Ankaliki, Dr. A. D. Kulkarni, Prof. Sujata I. Katti / IOSR Journal of Engineering (IOSRJEN) www.iosrjen.org

ISSN : 2250-3021

Vol. 2 Issue 2, Feb.2012, pp.356-362

placed at Bus-6 we get maximum net saving of Rs 60000. Table-5 gives the voltage profile of the system when second capacitor is placed at Bus-6. Without any compensation the total loss charges of the system is Rs. 20, 28,000 per annum. After placing two capacitors, we get a total of net saving Rs. 7,79,420 per annum. Fig. 4 gives the voltage profile of the system without compensation, First Level compensation \& Second Level compensation. The voltage profile is very much improved with Second Level compensation.

Table-4: Economical Comparison of Compensation

\begin{tabular}{|c|c|c|c|c|}
\hline $\begin{array}{c}\text { Bus } \\
\text { No. }\end{array}$ & $\begin{array}{c}\text { Optimum } \\
\text { kVAr }\end{array}$ & $\begin{array}{c}\text { Loss with } \\
\text { compensation } \\
\mathbf{k W}\end{array}$ & $\begin{array}{c}\text { Saving } \\
\text { in } \mathbf{k W}\end{array}$ & $\begin{array}{c}\text { Net saving } \\
\text { of cost in } \\
\text { Rs/annum }\end{array}$ \\
\hline $\boldsymbol{6}$ & $\mathbf{2 0 0}$ & $\mathbf{1 2 0}$ & $\mathbf{3 . 2 2}$ & $\mathbf{6 0 0 0 0}$ \\
\hline 7 & 200 & 92.58 & 2.21 & 30000 \\
\hline 8 & 200 & 120 & 2.039 & 29000 \\
\hline 9 & 200 & 97.2 & 2.98 & 50000 \\
\hline 10 & 200 & 120 & 2.75 & 48000 \\
\hline 11 & 100 & 120 & 1.07 & 16000 \\
\hline 12 & 100 & 150 & 1.56 & 29100 \\
\hline 13 & 100 & 180 & 1.65 & 31600 \\
\hline 14 & 100 & 130 & 1.61 & 30400 \\
\hline 15 & 100 & 150 & 1.85 & 36800 \\
\hline
\end{tabular}

Table-5: Voltage Profile with Second Level Compensation

\begin{tabular}{|c|c|}
\hline Bus No. & Bus Voltage in pu \\
\hline 1 & 1.0000 \\
\hline 2 & 0.9854 \\
\hline 3 & 0.9809 \\
\hline 4 & 0.9752 \\
\hline 5 & 0.9742 \\
\hline 6 & 0.9791 \\
\hline 7 & 0.9784 \\
\hline 8 & 0.9781 \\
\hline 9 & 0.9793 \\
\hline 10 & 0.9776 \\
\hline 11 & 0.9740 \\
\hline 12 & 0.9695 \\
\hline 13 & 0.9679 \\
\hline 14 & 0.9684 \\
\hline 15 & 0.9660 \\
\hline
\end{tabular}

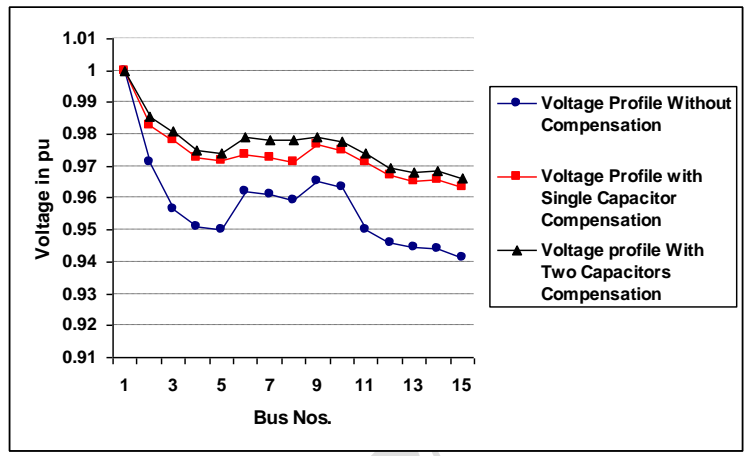

Fig. 4 Voltage Profile Without and With Compensation

\section{CONCLUSIONS}

This paper describes the hierarchical compensation technique for loss minimization in radial distribution system by optimum location of capacitor. By optimum hierarchical reactive compensation methodology with proper location and size on main feeder, laterals and sublaterals, optimized operating condition has been achieved. The cost analysis gives the amount of saving achieved per annum. The proposed approach is tested on 15 bus test radial distribution system. The technique serves as a useful tool for optimized distribution system operation.

\section{REFERENCES}

[1] Prabha Kundur, Power System Stability and Control McGraw Hill, 1994.

[2] M. Afsari, Singh S. P., Raju G. S., An Efficient Load Flow Technique for Radial Distribution Network, Proceedings of the $23^{\text {rd }}$ National Systems Conference, 1999, 394-397.

[3] Shiva. S, Srinivasulu. N, Vijaya Kumar M., A Novel approach in Radial Distribution Systems for Cost of Loss Reduction, Proceedings of the $25^{\text {th }}$ National Systems Conference (NSC),2001 234-240.

[4] Lee, S. H, and Grainer J. J, Optimum Placement of Fixed and Switched Capacitors on Primary Distribution Feeders, IEEE Trans., PAS-100, (1) 1981, 345-352.

[5] Grainger, J. J. \& Civanlar, S., Volt/var Control on Distributions Systems with Lateral Branches Using Shunt Capacitors and Voltage Regulators/ Part I, Part II, Part III: The overall problem" IEEE Trans., PAS - 104 (11) 1985, 3278-3283.

[6] Salama, M. M. and Chikhani, A. Y, A Simplified Network Approach to the VAR Control Problem for Radial Distribution Systems, IEEE Trans. Power Delivery, 8, (3), 1993,1529- 1535. 
Dr. S. G. Ankaliki, Dr. A. D. Kulkarni, Prof. Sujata I. Katti / IOSR Journal of Engineering (IOSRJEN)

www.iosrjen.org

ISSN : 2250-3021

Vol. 2 Issue 2, Feb.2012, pp.356-362

[7] Civanlar. S, Grainger J. J, Yin. H and Lee. S. S. $\mathrm{H}$, Distribution Feeder Reconfiguration for Loss reduction, IEEE Trans., Power Delivery, 1988,1217- 1223.

[8] Taylor, Lubkemand D., Implementation of Heuristic Search Strategies for Distribution Feeder Reconfiguration, IEEE Trans., Power Delivery, 1990, 239-246.

[9] Chis Salama M. M. and Jayaram S., Capacitor Placement in Distribution Systems using Heuristic Search Strategies, IEEE Proceedings Generation, Transmission and Distribution, Vol. 144, No. 3, 1997, 225-230.

[10] Abdel-Salam, T. S. Chikhani, A. Y. Hackam, R., A New Techniques for Loss Reduction Using Compensating Capacitors Applied to Distribution Systems with Varying Load Condition, IEEE Trans Power Delivery, Vol. 9, No.2, 1994, 819-827.

[11] V. B. Virulkar, D. G. Bhardwaj, "Reduction of Energy Losses by Computer Aided Distribution Planning” IE (I) Journal-EL, Vol. 80, PP 70-75, 1999.

[12] A. S. Pabla, Electric Power Distribution System, Tata McGraw Hill, 1983.

[13] Shekhappa Ankaliki, A. D. Kulkarni., Artificial Neural Network Based Distribution System Line Loss Estimation, International Journal of Logic Based Intelligent Systems (IJLBIS), Vol.3, No.2, July-December 2009, 119-131. 